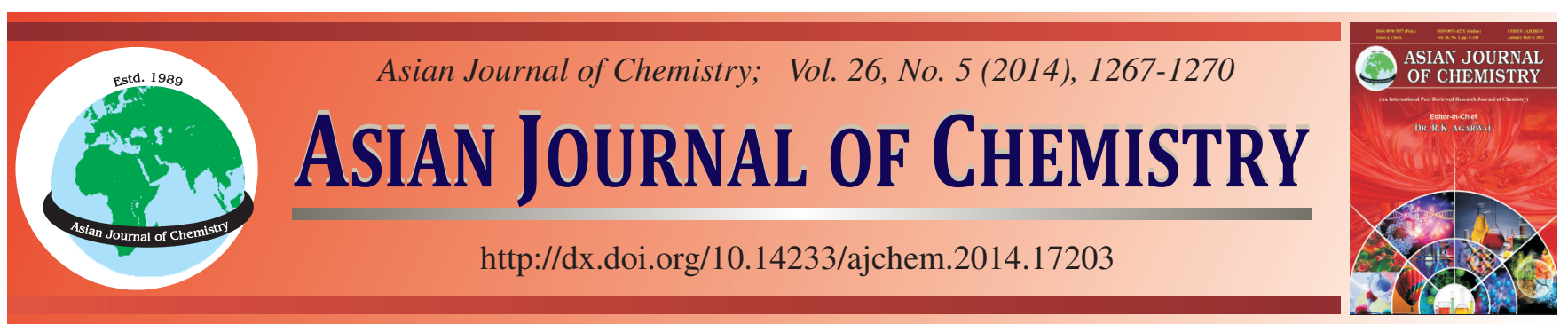

\title{
Different Chemical Composition of Aggregate Impact on Hydraulic Concrete Interfacial Transition Zone $\dagger$
}

\author{
YAN Shi ${ }^{*}$, Yun Dong, Lei Wang, XIA Chen and XIANG Li
}

Changjiang River Scientific Research Institute, Research Center of Water Engineering Safety and Disaster Prevention of Ministry of Water Resources, Wuhan 430010, Hubei Province, P.R. China

*Corresponding author: Fax: +86 27 82829752; 82926347; E-mail: shiyan@ mail.crsri.cn

Based on testing technology of SEM/EDS, microcosmic interfacial transition zone structure of hydraulic concrete of different aggregates were studied, such as limestone, basalt and sandstone. The results showed that used different aggregates in concrete, there were differences in element distribution and variation along the designated path in interfacial transition zone, as well as interface width. Enrichment of $\mathrm{Ca}(\mathrm{OH})_{2}$ in interfacial transition zone was affected by chemical and physical properties of aggregates, such as chemical composition and water absorption. The $\mathrm{Ca}(\mathrm{OH})_{2}$ enrichment degree and interface width were ordered, respectively as follow: sandstone $>$ basalt $>$ limestone and sandstone $>$ limestone $>$ basalt. Sandstone concrete has the weakest interface structure.

Keywords: Hydropower project, Aggregate variety, Hydraulic concrete, Interfacial transition zone.

\section{INTRODUCTION}

Aggregate accounted for $90 \%$ of hydraulic concrete mass, the maximum size of that may be as large as $150 \mathrm{~mm}$, hence the aggregates with different properties may have a significant even a decisive effect on the performance of hydraulic concrete ${ }^{1}$.

Concrete is a highly complex and non-homogeneous material and concludes three constituents, hardened cement paste, aggregate and interfacial transition zone (ITZ). The interfacial transition zone microstructure effect on the macroscopic properties of concrete can't be ignored. Previous studies have shown $n^{2-4}$ that the surface structure and mineral phases of aggregates may affect the nucleation growth of the hydration products especially calcium hydroxide and ettringite (AFt), which affects the microstructure of the interfacial transition zone and eventually influence mechanical properties and durability of concrete. However, there was a lack of information about the effects of aggregates with different properties on the interfacial transition zone structure.

In this paper, an attempt is made to analyze the interfacial transition zone microstructure of hardened concretes, whose commonly used artificial aggregates (limestone, basalt and quartzite) have contrasting chemical properties and the effects of different aggregates on the phase composition and elemental distribution of interfacial transition zone were also compared.

\section{EXPERIMENTAL}

A moderate heat portland cement (Jiahua Cement Plant, P.R. China), class F fly ash (FA), artificial aggregates, superplasticizer and air-entraining agent (Jiangsu Bote Company, P.R. China), water were used to produce all the concrete mixes. Three kinds of aggregate, namely limestone, basalt and quartzite, were chosen for the study. These were selected to have contrasting chemical and physical properties. The physical properties and chemical composition of aggregates are given in Tables 1 and 2.

Same mix proportions of four-graded dam concrete were shown in Table-3. Maintain the slump and air content of concrete in the range of 50-70 $\mathrm{mm}$ and 3.5-4.5\%. The varieties of fine and coarse aggregate were consistent in the same concrete.

Concretes were mixed according to SL 352-2006 (test code for hydraulic concrete, China). All concretes were casted in $150 \mathrm{~mm} \times 150 \mathrm{~mm} \times 150 \mathrm{~mm}$ steel molds and demolded at 1 day. The specimens subsequently cured in a fog room. On $28^{\text {th }}$ day, some specimens were crushed and the others were cut into $15 \mathrm{~mm}$-thick slices. The selected crushed pieces containing the cement matrix and interfacial transition zone were analyzed by SEM/EDS.

†resented at The 7th International Conference on Multi-functional Materials and Applications, held on 22-24 November 2013, Anhui University of Science \& Technology, Huainan, Anhui Province, P.R. China 
TABLE-1

PHYSICAL PROPERTIES OF AGGREGATES

\begin{tabular}{ccccccc}
\hline \multirow{2}{*}{ Aggregate variety y } & \multicolumn{2}{c}{ Apparent density $\left(\mathrm{kg} \mathrm{m}^{-3}\right)$} & \multicolumn{2}{c}{ Saturated surface dry water absorption $(\%)$} & FM & \multicolumn{2}{c}{ Stone powder content (\%) } \\
\cline { 2 - 7 } & $\leq 5 \mathrm{~mm}$ & $5-20 \mathrm{~mm}$ & $\leq 5 \mathrm{~mm}$ & $5-20 \mathrm{~mm}$ & $\leq 5 \mathrm{~mm}$ & $\leq 5 \mathrm{~mm}$ \\
\hline Limestone & 2710 & 2720 & 0.84 & 0.32 & 2.9 & 13.1 \\
Basalt & 2910 & 2930 & 0.91 & 0.35 & 2.6 & 14.0 \\
Sandstone & 2690 & 2700 & 1.60 & 0.85 & 3.0 & 12.8 \\
\hline
\end{tabular}

TABLE 2

CHEMICAL COMPOSITION OF AGGREGATES (\%)

\begin{tabular}{cccccc}
\hline Aggregate variety & $\mathrm{CaO}$ & $\mathrm{MgO}$ & $\mathrm{Fe}_{2} \mathrm{O}_{3}$ & $\mathrm{Al}_{2} \mathrm{O}_{3}$ & $\mathrm{SiO}_{2}$ \\
\hline Limestone & 52.8 & 3.0 & 1.9 & 2.4 & 12.20 \\
Basalt & 9.31 & 4.92 & 13.50 & 12.13 & 49.94 \\
Sandstone & 4.56 & 1.28 & 5.73 & 12.34 & 69.66 \\
\hline
\end{tabular}

\begin{tabular}{ccccc}
\multicolumn{5}{c}{ TABLE 3 } \\
\hline $\begin{array}{c}\text { W/C } \\
\text { ratio }^{*}\end{array}$ & $\begin{array}{c}\text { FA }^{*} \\
(\%)\end{array}$ & $\begin{array}{c}\text { Water } \\
\left(\mathrm{kg} \mathrm{m}^{-3}\right)\end{array}$ & $\begin{array}{c}\text { Sand } \\
\text { ratio** } \\
(\%)\end{array}$ & $\begin{array}{c}\text { Aggregate gradation } \\
150 \mathrm{~mm}):(40-80 \mathrm{~mm}): \\
(20-40 \mathrm{~mm}):(5-20 \mathrm{~mm})\end{array}$ \\
\hline 0.45 & 30 & 82 & 25 & $30: 30: 20: 20$ \\
\hline
\end{tabular}

"By mass. ${ }^{* *}$ By volume.

\section{RESULTS AND DISCUSSION}

Effect of aggregate variety on compressive strengths of concrete: The compressive strength results included of different aggregate concretes at $28 \mathrm{~d}$ shown in Table- 4 . The order of the strength was as follows:

Basalt concrete $>$ Limestone concrete $>$ Sandstone concrete

\section{TABLE-4}

COMPRESSIVE STRENGTH RESULTS OF DIFFERENT AGGREGATE CONCRETES AT $28^{\text {th }}$ DAY

\begin{tabular}{cccc}
\hline Aggregate variety & Limestone & Basalt & Sandstone \\
\hline $\begin{array}{c}\text { Compressive strength } \\
(\mathrm{MPa})\end{array}$ & 35.1 & 37.6 & 29.3 \\
\hline
\end{tabular}

Elements enrichment analysis: Element maps of referenced concrete with different aggregates were shown in Fig. 1, semi-quantitative results of concrete microstructure were shown in Table-5. The distribution of $\mathrm{Al}, \mathrm{Si}, \mathrm{Ca}, \mathrm{Fe}$ in the interfacial transition zone contains adjacent aggregate and cement matrix were analyzed. From top to bottom of the colour bar on the left, the degree of element enrichment was gradually decreased. The white colour represents fully enrichment, while the black colour represents the element does not exist in this area.

It is revealed that the $\mathrm{CaO}$ and $\mathrm{SiO}_{2}$ phase dominate in the cement matrix and interfacial transition zone, which constitute $75 \%$ of the total mass, but the elements distribution in concretes are discontinuous and uniform. Limestone is an alkaline calcareous aggregate, which shows white or red in the map of Ca element and appeared dark blue or black in the map of Si element. While in the cement matrix, the content of $\mathrm{Si}, \mathrm{Al}, \mathrm{Mg}$ element increases with cement hydration and there are more hydration products in the cement matrix zone than that in the interfacial transition zone. Basalt and sandstone are weakly acidic siliceous aggregates, those major element is $\mathrm{Si}$, so there was opposite results at $\mathrm{Si}$ or $\mathrm{Ca}$ map with limestone. Moreover, the Ca elements obviously enriched in the interfacial transition zone of sandstone concrete and there was little content of Ca element in the interfacial transition zone of basalt concrete.

$\mathrm{The} \mathrm{Ca} / \mathrm{Si}$ ratio of interfacial transition zone in different concretes can also verified, that the sequence of $\mathrm{Ca}$ enrichment is sandstone $>$ Basalt $>$ limestone. The $\mathrm{Ca} / \mathrm{Si}$ ratio will significantly increased if $\mathrm{Ca}(\mathrm{OH})_{2}$ or ettringite content of is higher in the interfacial transition zone, because the $\mathrm{Ca} / \mathrm{Si}$ ratio of $\mathrm{C}-\mathrm{S}-\mathrm{H}$ gel is only $1.3-1.8^{5}$. For sandstone, basalt and limestone concretes, the $\mathrm{Ca} / \mathrm{Si}$ ratios of interfacial transition zone, respectively were $2.29,1.62$ and 1.35 , while the $\mathrm{Ca} / \mathrm{Si}$ ratios of the cement matrix were 1.33, 1.43 and 1.31 .

Meanwhile, the $\mathrm{FeO}$ phase enriched in the interfacial transition zone to some extent, the $\mathrm{FeO}$ content is higher in this region than in the paste, which was more obvious for limestone concrete. Aligizaki and Rooij ${ }^{6}$ concluded that iron enrichment is an important feature in the interfacial transition zone and the 900-1300 $\mu \mathrm{m} \mathrm{Fe}$ ions around aggregates migrates towards interfacial transition zone where the $\mathrm{pH}$ value is much higher. Therefore, particular emphasis should be paid on erosion problem around the interfacial transition zone caused by $\mathrm{Fe}$ ions in the reinforced concrete.

Distribution of main elements in the interfacial transition zone: Distribution of $\mathrm{Ca}, \mathrm{Si}, \mathrm{Al}, \mathrm{Mg}$ and Fe elements in the interfacial transition zone of different concretes were shown in Fig. 2. The paths pass through from the aggregate to the cement matrix area, as the arrows instructed. The $\mathrm{X}$-axis and Y-axis at element distribution map, respectively represents specified path distance and elemental mass ratio.

The results showed that the chemical properties of aggregates have a great effect on the elemental distribution. The peak of Ca element is significant in the region of limestone aggregate, while Si element has the highest proportion in the

\begin{tabular}{|c|c|c|c|c|c|c|c|}
\hline \multicolumn{8}{|c|}{$\begin{array}{c}\text { TABLE } 5 \\
\text { SEMI-QUANTITATIVE RESULTS OF CONCRETE MICROSTRUCTURE }\end{array}$} \\
\hline \multirow{2}{*}{$\begin{array}{l}\text { Aggregate } \\
\text { variety }\end{array}$} & \multirow{2}{*}{ Zone } & \multicolumn{5}{|c|}{ Chemical composition (\%) } & \multirow{2}{*}{$\mathrm{Ca} / \mathrm{S}$} \\
\hline & & $\mathrm{CaO}$ & $\mathrm{SiO}_{2}$ & $\mathrm{Al}_{2} \mathrm{O}_{3}$ & $\mathrm{FeO}$ & $\mathrm{MgO}$ & \\
\hline \multirow{2}{*}{ Limestone } & Paste & 43.8 & 33.37 & 14.37 & 1.7 & 1.71 & 1.31 \\
\hline & ITZ & 42.91 & 31.89 & 12.11 & 5.78 & 2.37 & 1.35 \\
\hline \multirow{2}{*}{ Basalt } & Paste & 48.95 & 34.12 & 6.77 & 2.59 & 3.63 & 1.43 \\
\hline & ITZ & 54.11 & 33.46 & 5.58 & 3.66 & 1.71 & 1.62 \\
\hline \multirow{2}{*}{ Sandstone } & Paste & 48.51 & 36.56 & 4.6 & 3.41 & 3.87 & 1.33 \\
\hline & ITZ & 58.18 & 25.42 & 7.8 & 3.95 & 1.33 & 2.29 \\
\hline
\end{tabular}




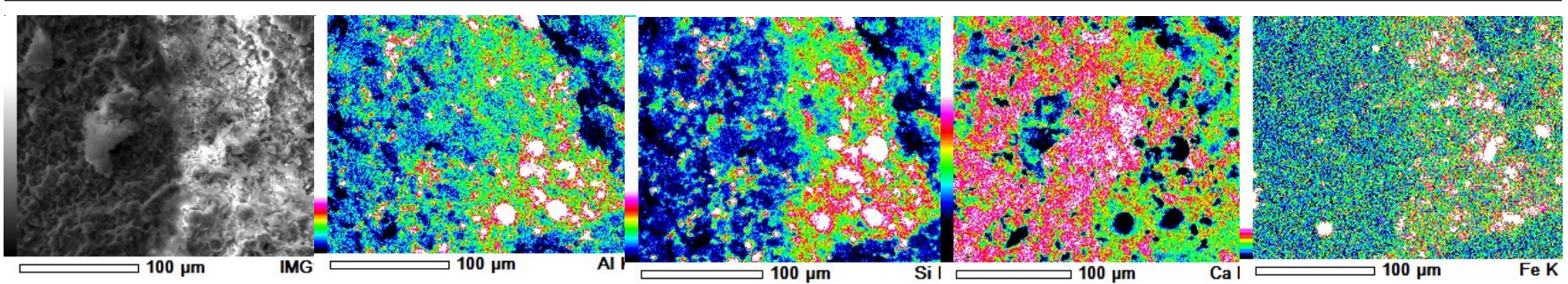

(a) Limestone concrete

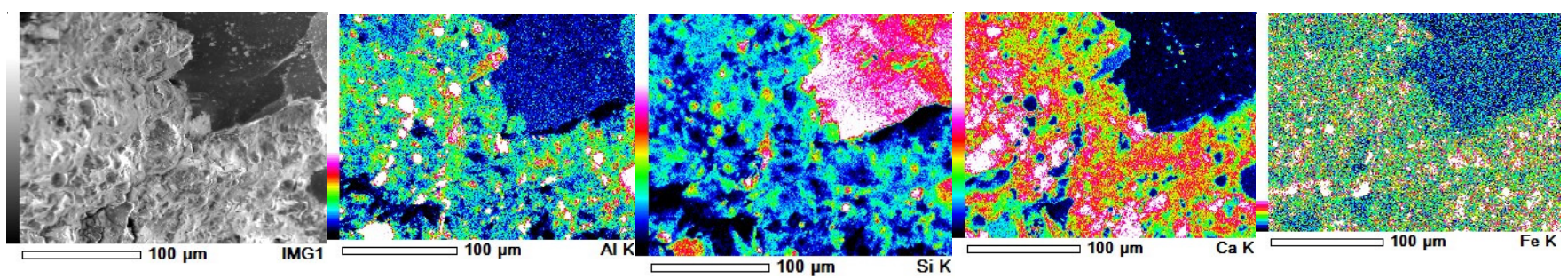

(b) Basalt concrete

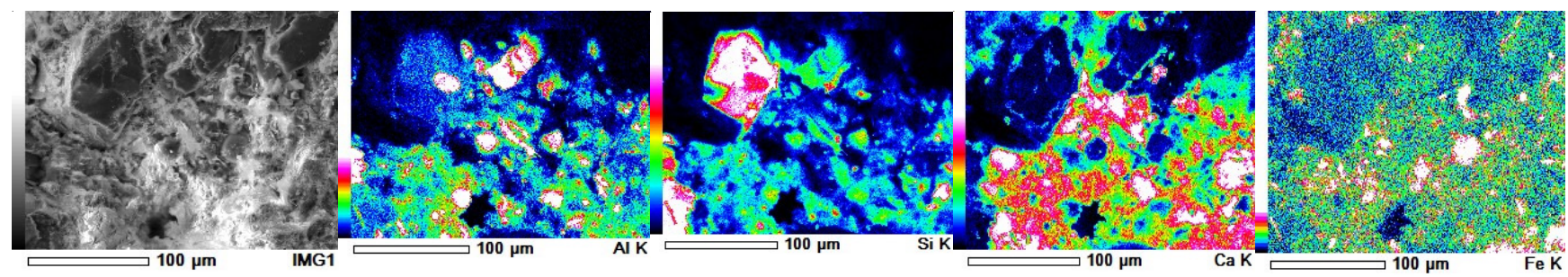

(c) Sandstone concrete

Fig. 1. Element maps of referenced concrete with different aggregates

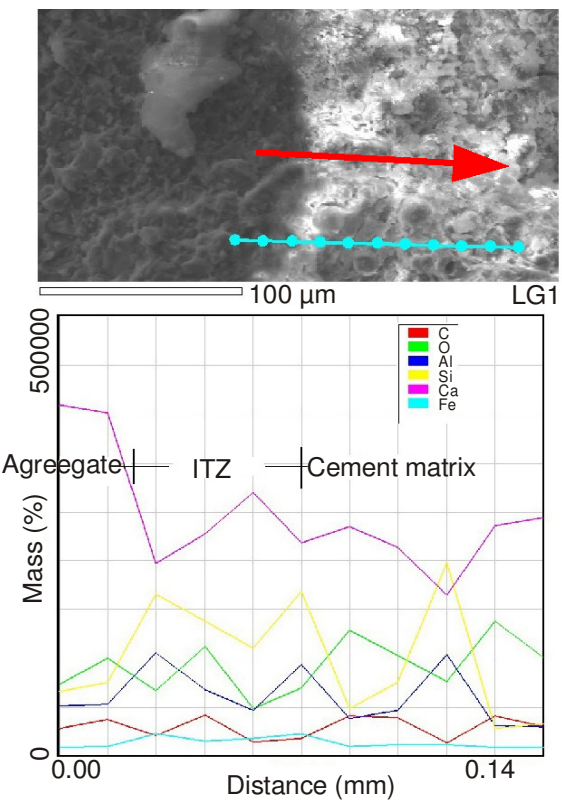

(a) Limestone concrete

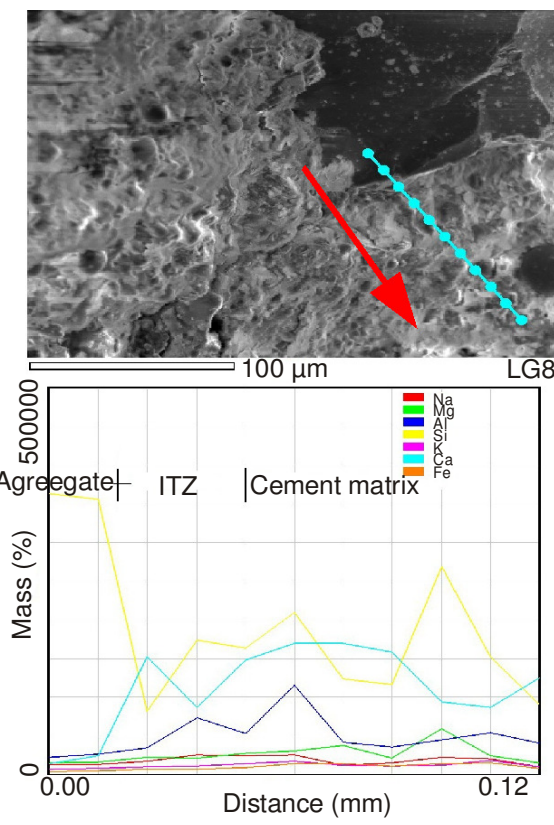

(b) Basalt concrete

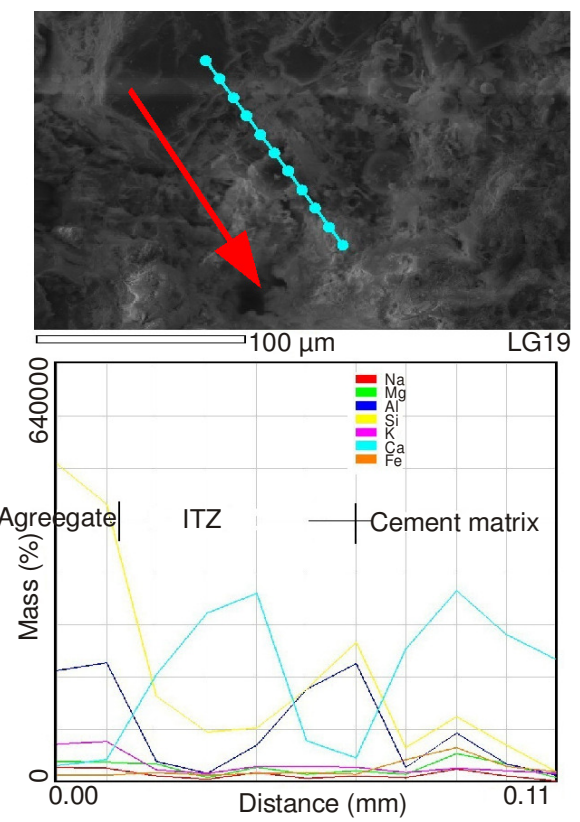

(c) Sandstone concrete

Fig. 2. Distribution of the elements in the interfacial transition zone and width division

areas of basalt and sandstone aggregate. Tending to interfacial transition zone away from aggregates, the Ca content of limestone concrete obviously decline and that of basalt concrete was relatively stable, only in the interfacial transition zone of sandstone concrete the $\mathrm{Ca}(\mathrm{OH})_{2}$ enrichment can be clearly observed. In the cement paste, there was a typical increase in elements $\mathrm{Si}$ and $\mathrm{Al}$, which was in good consistency with the above semi-quantitative results.
Based on the adsorption theory, sandstone and basalt aggregates are weakly acidic, which adsorb preferential $\mathrm{Ca}^{2+}$ ions during the cement hydration, so the $\mathrm{Ca}(\mathrm{OH})_{2}$ crystals prone to nucleate and grow on the surface of this aggregate. However, water absorption of limestone and basalt aggregate used here is lower, so the migration ability of $\mathrm{Ca}^{2+}$ ions to the interfacial transition zone is relatively weak, thus $\mathrm{Ca}(\mathrm{OH})_{2}$ enrichment rarely happened in the limestone and basalt 
interfacial transition zone. Previous studies showed that the crystals such as $\mathrm{Ca}(\mathrm{OH})_{2}$ and ettringite enrichment will reduce the density of interface structure, thus weakening the load bearing capacity of concrete . $^{7}$

According to the element distribution and variation of main elements along the specified path, the interfacial transition zone width in different concretes can be roughly determined, as shown in Fig. 2. For sandstone concrete, the interfacial transition zone width can be detected from the distance between enrichment peaks of Ca element, $55 \mu \mathrm{m}$. Limestone and basalt interfacial transition zone have the width 45 and 40 $\mu \mathrm{m}$, which estimated by the variation in $\mathrm{Si}$ and $\mathrm{Al}$ contents since the not obvious Ca enrichment. Therefore, the interfacial transition zone width ordered as follows:

Sandstone concrete $>$ Limestone concrete $>$ Basalt concrete

It is revealed that the interfacial transition zone was related to the enrichment degree of $\mathrm{Ca}(\mathrm{OH})_{2}$. The more obvious enrichment, the greater interfacial transition zone width and the weaker mechanical properties of interfacial transition zone. The $\mathrm{Ca}(\mathrm{OH})_{2}$ enrichment was influenced by the chemical and physical properties (such as water absorption) of aggregates. Thus, aggregate affect the element distribution, the interfacial transition zone width and the paths variation of the main elements, thus affect the interfacial transition zone structure and the concrete strength.

\section{Conclusion}

Based on the research results, the following conclusions can be drawn. Used different aggregates in hydraulic concrete, there were differences in element distribution and variation along the designated path in interfacial transition zone, as well as interface width. Enrichment of $\mathrm{Ca}(\mathrm{OH})_{2}$ in interfacial transition zone was affected by chemical and physical properties of aggregates. The $\mathrm{Ca}(\mathrm{OH})_{2}$ enrichment degree and interface width were ordered, respectively as follow:

Sandstone $>$ Basalt $>$ Limestone and

Sandstone $>$ Limestone $>$ basalt

So, sandstone concrete has the weakest interface structure. The results help to analyze the macroscopic properties of concrete.

\section{ACKNOWLEDGEMENTS}

This research is financially supported by the National Natural Science Foundation of China (No. 51109015, 51139001 and 51279017), the Twelfth five-year Science and Technology support program (No. 2011BAE27B01).

\section{REFERENCES}

1. ACI Committee 209, Prediction of Creep, Shrinkage and Temperature Effects in Concrete Structures, 209R: Manual of Concrete Practice, Part 1 (1992).

2. H.-S. Chen, W. Sun and P. Stroeven, J. Chinese Ceramic Soc., 32, 72 (2004). (in Chinese).

3. W.A. Tasong, C.J. Lynsdale and J.C. Cripps, Cement Concr. Res., 28, 1453 (1998).

4. G.A. Rao and B.K.R. Prasad, Cement Concr. Res., 32, 253 (2002).

5. Y. Yunzhang, Science of Cementitious Materials, Wuhan University of Technology Press, edn 2, vol. 2, p. 125 (2003).

6. K.K. Aligizaki, M.R. de Rooij and D.D. Macdonald, Cement Concr. Res., 30, 1941 (2000).

7. C. Xia, Wuhan Univ. Changjiang River Sci. Res. Institute, 6, 108 (2011). 